AUTOR:

FÁBIO ROBERTO CABAR

ORIENTADOR:

Prof. Dr. Pedro Paulo Pereira

\title{
Concentração sérica do fator de crescimento vascular endotelial e a profundidade da invasão trofoblástica na parede tubária em gestações ampulares
}

\author{
Serum concentration of the vascular endothelial growth factor and the \\ depth of trophoblastic invasion into the tubal wall in ampular pregnancies
}

\section{Resumo de tese}

Palavras-chave

Gravidez ectópica

Gravidez tubária

Fatores de crescimento do endotélio

vascular

Gonadotropina coriônica humana Subunidade beta

Keywords

Ectopic, pregnancy

Tubal, pregnancy

Vascular endothelial growth factors Human chorionic gonadotropin

Beta subunit
Tese apresentada ao Departamento de Obstetrícia e Ginecologia da Faculdade de Medicina da Universidade de São Paulo, em 26 de novembro de 2008

OBJETIVO: relacionar a profundidade de penetração do tecido trofoblástico na parede tubária acometida por gestação ampular à concentração sérica materna de VEGF. Avaliar a possibilidade do VEGF predizer a profundidade da invasão do tecido trofoblástico, comparando o desempenho do VEGF ao desempenho da concentração sérica de $\beta$-hCG na predição da profundidade da invasão do trofoblasto. MÉTODOS: estudo prospectivo desenvolvido de dezembro de 2006 a setembro de 2007. Foram incluídas 30 pacientes com gestação ampular submetidas à salpingectomia. Foram dosadas concentrações séricas de VEGF antes da salpingectomia. Classificação histológica da invasão trofoblástica: grau I, quando limitada à mucosa da tuba uterina; grau II, até a camada muscular; grau III, invasão de toda a espessura da tuba uterina. RESULTADOS: dez pacientes infiltração grau I, nove pacientes grau ll e 11 pacientes grau III. Os diferentes graus de invasão apresentaram diferença significativa nas concentrações de VEGF ( $p<0,001)$. Concentração de VEGF $305 \mathrm{pg} / \mathrm{mL}$ apresentou sensibilidade de 100,0\%, especificidade de $85,0 \%$, valor preditivo positivo de 76,9\%, valor preditivo negativo de 100,0\% para determinar invasão trofoblástica grau I. A concentração de VEGF 425,9pg/mL foi o melhor ponto de corte para predição de invasão grau III: sensibilidade $81,8 \%$, especificidade $94,7 \%$, valor preditivo positivo $90,0 \%$, valor preditivo negativo $90,0 \%$. A regressão logística selecionou concentração sérica de VEGF como fator de melhor desempenho na predição da invasão trofoblástica quando comparado à concentração de $\beta$-hCG. CONCLUSÕES: a profundidade da penetração do trofoblasto na parede tubária com gestação ampular se relaciona à concentração sérica de VEGF. Esta concentração é preditora da profundidade da invasão do trofoblasto e apresenta melhor desempenho que a concentração sérica de $\beta$-hCG como preditora da profundidade da invasão do trofoblasto na parede da tuba uterina acometida por gestação ampular. 